\title{
Percepción del paisaje desde la mirada del turista de algunos espacios de transformación urbana de Medellín, Colombia
}

\section{Landscape Perception from the Tourist's View of Some Urban Transformation Spaces of Medellin, Colombia}

Percepção da paisagem desde o olhar do turista de alguns espaços de transformação urbana de Medellín, Colômbia

Ledys Vianey López Zapata*

Wilmar Mauricio Sepúlveda**

Johan Sebastián Gómez Gómez ***

Recibido: 29 de abril de 2017

Aprobado: 13 de diciembre de 2017

Doi:

Para citar este artículo:

López-Zapata, L. V., Sepúlveda, W. M., \& Gómez-Gómez, J. S. (2018). Percepción del paisaje desde la mirada del turista de algunos espacios de transformación urbana de Medellín, Colombia. Territorios (39), 175-201. Doi:

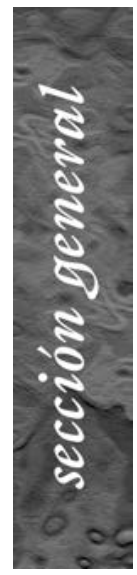

* Docente asociada, Facultad de Administración, integrante del Grupo de Investigación Empresarial y Turístico GIET, Institución Universitaria Colegio Mayor de Antioquia. Estudiante de doctorado en turismo en la Universidad Islas Baleares. Magister en Estudios urbano-regionales, Universidad Nacional de Colombia, sede Medellín. Especialista en Alta Gerencia, Universidad de Medellin. Administradora de Empresas turísticas, Institución Universitaria Colegio Mayor de Antioquia. Correo electrónico: ledys.lopez@colmayor.edu. co. ORCID: http://orcid. org/0000-0001-7714-5740

** Docente investigador del Grupo de Investigación Empresarial y Turistico giet, Institución Universitaria Colegio Mayor 
Palabras clave

Transformaciones urbanas, relaciones comunicacionales y comerciales, territorios informales, slum tourism, actitud de la población.
Keywords

Urban transformations, communication and trade relations, informal territories, slum tourism, population's attitude.

Palavras-chave

Transformações urbanas, relações comunicacionais e comerciais, territórios informais, slum tourism, atitude da população.

tersitarios 39

176

\section{RESUMEN}

Las políticas de intervención urbana han contribuido con la revitalización de diferentes ciudades alrededor del mundo, lo que genera zonas con vocación para el turismo en territorios transformados urbanísticamente y algunos con características de asentamientos precarios. Este artículo presenta los resultados de la investigación sobre la percepción del visitante en los territorios de transformación urbana de Medellín, Colombia, se utiliza una estrategia de investigación descriptiva de enfoque mixto. Como principales hallazgos se encuentra que las zonas de estudio son frecuentadas principalmente por turistas internacionales (68\%), los cuales presentan mayores niveles de interacción con la población local $(67 \%)$ y consumen con mayor frecuencia productos y servicios ofrecidos por estos $(65 \%)$.

\section{ABSTRACT}

The urban intervention policies have contributed to the revitalization of different cities around the world, generating tourism-focused areas in urbanistically transformed territories and some with characteristics of precarious settlements. This article presents the results of the research on the visitor's perception in the territories of urban transformation in Medellin, Colombia. A descriptive research strategy of mixed approach was used. The main findings show that the study areas are frequented by international tourists $(68 \%)$, who have higher levels of interaction with the local population $(67 \%)$ and consume more frequently products and services offered by this local population $(65 \%)$.

\section{RESUMO}

As políticas de intervenção urbana têm contribuído com a revitalização de diferentes cidades ao redor do mundo, gerando zonas com vocação para o turismo em territórios transformados urbanisticamente e alguns com características de assentamentos precários. Este artigo apresenta os resultados da pesquisa a percepção do visitante nos territórios de transformação urbana de Medellín, Colômbia, se utiliza uma estratégia de pesquisa descritiva de enfoque misto. Como principais resultados se encontra que as zonas de estudo são frequentadas principalmente por turistas internacionais $(68 \%)$, os quais apresentam maiores níveis de interação com a população local (67\%) e consumem com maior frequência produtos e serviços oferecidos pelos mesmos (65\%). 


\section{Introducción}

El proceso de urbanización experimentado en las ciudades latinoamericanas desde la década del ochenta se caracterizó por ser de transición demográfica acelerado, con una primacía urbana, es decir, alto grado de concentración demográfica y económica en torno a una gran ciudad y, por consiguiente, un cambio en la estructura económica de la mayoría de los centros urbanos (Giraldo, García, Ferrari \& Bateman, 2009).

La ciudad de Medellín no ha sido ajena a estos procesos y, por tanto, desde el Plan de Ordenamiento Territorial (РОT) aprobado en el año 1999, la ciudad replantea su modelo económico y físico. Desde el punto de vista económico, se genera un cambio de vocación productiva migrando de la tradición industrial hacia la venta de una plataforma de servicios financieros, turísticos y médicos.

Desde el modelo físico, la ciudad redefine sus territorios estratégicos para apuntarle al reto de ciudad competitiva, una ciudad que se inserta en las lógicas globales por medio de estrategias como la recuperación de los centros históricos, la conversión del espacio público en tema político y la importancia dada al transporte masivo (Arango, 2009) y a los medios alternativos de transporte, así como la recuperación estética de zonas degradadas mediante políticas de embellecimiento de techos y fachadas. Las anteriores manifestaciones son una expresión física de la apuesta por la internacionalización de las ciudades latinoamericanas.

Los territorios objeto de esta investigación se caracterizan por haber sido objeto de transformaciones urbanas como las mencionadas anteriormente, donde a partir de la intervención del Estado mediante una obra de infraestructura o proyecto urbano, estos adquieren una función turística y, por tanto, el turista comienza a ser un actor importante para comprender las lógicas y relaciones entre anfitriones y visitados que se tejen en estos espacios, algunos de ellos caracterizados por tener procesos de urbanización informal o incompleta, otros por ser zonas de transición urbano - rural o por ser zonas de renovación urbana-.

Esta investigación toma algunos aspectos de la percepción del turista de cuatro espacios de transformación urbana de $\mathrm{Me}$ dellín específicamente, aquellas variables relacionadas con la percepción estética y social.

Para analizar la percepción del visitante se desarrolló trabajo de campo y aplicación de cuestionarios a visitantes nacionales y extranjeros en las zonas seleccionadas. Se realizó un muestreo aleatorio simple y sistemático, para población flotante, con un tamaño de muestra de 384 turistas, con una confiabilidad del $95 \%$ y un error del $5 \%$, aplicando la fórmula de población infinita.

Este artículo se estructura con: una breve revisión de literatura que soporta la selección de las zonas y las variables a trabajar; la metodología desarrollada; una contextualización de la ciudad utilizada to a Magister en Administración, Universidad Pontificia Bolivariana. Administrador de Empresas Turísticas, Institución Universitaria Colegio $\mathrm{Ma}$ yor de Antioquia. Correo electrónico: wilmar.sepulveda@colmayor.edu.co. ORCID: http://orcid. org/0000-0002-9361-8576

***Catedrático, Institución Universitaria Colegio Mayor de Antioquia. Candidato a Magister en Estudios urbano-regionales, Universidad Nacional de Colombia, sede Medellín. Administrador de Empresas Turisticas, Institución Universitaria Colegio Mayor de Antioquia. Correo electrónico: johan.gomez@ colmayor.edu.co. ORCID: http://orcid.org/00000001-8171-1450

territarias 39

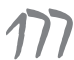


como caso de estudio y las zonas seleccionadas, y finaliza con los resultados y conclusiones.

\section{Revisión de la literatura}

\subsection{Transformación urbana}

Comprender los procesos de transformación urbana requiere revisar los diferentes abordajes teóricos bajo los cuales se ha trabajado este concepto.

Un primer abordaje para comprender la transformación es aquella línea de investigación que la concibe como un proceso ligado al fenómeno de la globalización. Según este abordaje "las transformaciones territoriales son una variable dependiente de un conjunto de transformaciones sociales y económicas en el ámbito global, que se traducen espacialmente en la modificación del rol y las funciones de los espacios urbanos" (Guevara, 2015, p. 6). Las ciudades se transforman como resultado de las presiones del capital global, reformulando su rol hacia la economía de servicios avanzados. Este cambio de rol al interior de las ciudades tiene impactos directos sobre la forma y estética de los espacios urbanos donde con mayor frecuencia se busca hacer de estos, lugares para las clases creativas.

Una segunda línea de investigación para comprender las transformaciones urbanas se ubica en los procesos sociológicos de las transformaciones territoriales, "haciendo hincapié en la localización de los diferentes sectores sociales en el espacio y la relación entre sus localizaciones"
(Guevara, 2015, p. 10). Bajo esta línea, la transformación se da a partir de la comprensión de las condiciones habitacionales de los individuos y la distribución desigual de estos en el espacio. Esta línea se conoce como la segregación social y es a partir del mapeo de las condiciones sociales y económicas que se definen las intervenciones en el territorio con el fin de cerrar las brechas o fronteras entre comunidades.

La tercera línea de investigación aborda los procesos de transformación desde áreas o sectores de la ciudad bajo la lógica espacial como consecuencia del crecimiento y la expansión urbana que se materializa en los procesos de gentrificación y difusión. El primero está asociado con las transformaciones que se dan en las áreas centrales de la ciudad como consecuencia de un proceso de revitalización y recuperación de zonas deterioradas o degradadas ambientalmente. El segundo - la difusión urbana- está asociada con las transformaciones que se producen por la expansión acelerada de las ciudades (Guevara, 2015).

A partir de los abordajes teóricos sobre transformación urbana planteados en los párrafos anteriores se infiere que los procesos llevados a cabo en la ciudad de Medellín se enmarcan en la primera y segunda línea. Los procesos de transformación de las zonas Carabobo Norte y Metrocable Arví obedecen a las lógicas del mercado global donde se reformula su rol de tradición agrícola o industrial hacia una plataforma de servicios, entre ellos los de turismo. Por su parte, la transformación de las zonas Metrocable Santo Domingo 
y zona de influencia en la comuna 1 y Escaleras eléctricas Comuna 13 obedece a la segunda línea donde a partir del análisis de los indicadores de calidad de vida de los individuos que habitan estas zonas se definen las intervenciones, con el fin de cerrar la brecha de la desigualdad social.

El marco legal de estos procesos de transformación urbana en Colombia lo establece la Ley 388 de 1997 mediante la cual se implementaron los tratamientos de renovación, redesarrollo y mejoramiento integral de barrios como medidas de intervención en el suelo urbano y de revitalización de zonas deterioradas o con vocaciones en desuso, lo cual ha implicado profundos procesos de transformación de algunos espacios dentro de la ciudad considerados estratégicos, bien sea por su ubicación geográfica en el contexto urbano o por los potenciales usos que allí se pueden dar (López, Sepúlveda, \& Gómez, 2015). En el caso específico de la ciudad de Medellín, la figura de proyectos urbanos integrales (PUI) ha sido un método novedoso de gestión y planificación de la ciudad que surge como respuesta a la crisis económica y social.

Los PUI tuvieron como objetivo reemplazar la visión tradicional de la "ciudad industrial” por una visión más dinámica, creativa y atractiva. El turismo surgió como consecuencia de las actuaciones en el espacio urbano y rural que motivaron el consumo y realización de actividades de esparcimiento y recreación en zonas deprimidas fomentadas principalmente por el gobierno local de manera estratégica.

\subsection{Percepción del paisaje}

Los estudios sobre percepción son fundamentales para planificar el turismo en cualquier territorio (Ríos-Milagres \& Barbosa, 2012). Pueden ser utilizados para indagar sobre la forma en la que visitantes y anfitriones conciben el turismo, las interacciones entre cada actor y las transformaciones sobre el paisaje.

La percepción es una fase evaluativa resultado de la experiencia sensorial donde confluyen, por un lado, los estímulos físicos y las sensaciones y, por otro, el proceso de estructuración de esa información que captan los sentidos mediante la selección y organización de dichos estímulos y sensaciones (Nogué, 1992; Vargas, 1994). Comprende las actitudes y preferencias a partir de lo captado por los sentidos y estructurado por la mente.

La percepción es un proceso tanto cognitivo como psíquico, es decir, incluye tanto la mente consciente como la inconsciente. Así mismo, es un proceso, cambiante, subjetivo y selectivo donde entran en juego aprendizajes y experiencias previas, referentes ideológicos, culturales e históricos, los cuales son aplicados a las experiencias cotidianas para ordenarlas e interpretarlas (Vargas, 1994). Así, la subjetividad y selectividad se convierten en características esenciales de la percepción humana y de la formación del pensamiento simbólico que orienta la manera como los grupos sociales se apropian del entorno.

Los estudios de percepción del paisaje pueden ser individuales o colectivos: Estos territarios 39

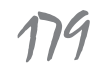


últimos, según las variables seleccionadas y el objeto del investigador, pueden ser estudios de percepción social, estéticos, simbólicos o basados en las emociones.

Los estudios de percepción social se basan en la noción de la existencia de múltiples grupos sociales en el territorio y, por tanto, multitud de percepciones y de comportamientos en relación con el paisaje. En los territorios que adquieren función turística, los turistas deben ser considerados un grupo social. Como grupo, reaccionan de forma parecida hacia el lugar que visitan y en la mayoría de los casos establecen una relación totalmente superficial con el nuevo entorno (Nogué, 1992).

La percepción del paisaje por parte del turista está condicionada por sus esquemas culturales a partir del lugar de orgien y, por tanto, su lugar de procedencia (nacionales o internacionales) es una variable dependiente del proceso de percepción. Los paisajes percibidos por los turistas serán analizados e interpretados desde sus habituales estructuras y categorías donde sus estructuras mentales apenas se verán trastocadas por las nuevas experiencias vividas (Nogué, 1992).

En los estudios territoriales y de planificación, el tema de percepción del paisaje es fundamental para una coherente intervención en el territorio, donde se requiere trascender la escala de la percepción individual a la colectiva. Esta última es mucho más compleja y es fuertemente influenciada por la cultura, por el contexto espacio-temporal y por la historicidad de las prácticas sociales presentes en el territorio. Por lo tanto, en un mismo espacio se pueden dar diversas lecturas del paisaje en función de los diferentes grupos sociales existentes (Nogué, 1992).

En este contexto, el paisaje se entiende como recurso turístico que representa la cultura, es decir, es el elemento tangible que refleja las formas de vida de quienes habitan esos espacios, es el aspecto visible y perceptible del espacio y es un elemento consustancial del fenómeno turístico. Paisaje y turismo son, por tanto, dos realidades íntimamente relacionadas (Nogué, 1989). El turista actúa como un consumidor del paisaje. Este consumo se da no solo a partir de la percepción señorial, sino también a partir de las interacciones, las cuales pueden ser de tipo comunicacional o comercial.

La primera hace referencia a las relaciones dialógicas igualitarias que establece el visitante con la población local, lo que posibilita un aprendizaje mutuo. La segunda comprende los actos de compra y adquisición de bienes y servicios requeridos por el turista en el lugar. Las relaciones comerciales también contribuyen a la formación de la percepción del paisaje observado por parte del turista a partir de la oferta comercial existente

La percepción del territorio visitado que cada individuo o grupo social construye es una interpretación sesgada de la realidad, enmarcada en una ubicación espacial y temporal a partir de la situación histórico-social del lugar visitado y de las vivencias y experiencias de quien observa y asiste (Vargas, 1994). 
Su interpretación no es una copia fiel de la realidad, sino una representación parcial de dicho entorno a partir de los valores culturales; lugar de procedencia, experiencias previas del visitante, interacción con el paisaje y aspiraciones. Los cuales constituyen los referentes perceptuales bajo los cuales se valora y califica el paisaje. Mediante la percepción se realiza el proceso de apreciación y apropiación subjetiva de la realidad.

\subsection{Slum tourism}

Las definiciones sobre esta forma de turismo son vagas y siempre relacionadas con un contexto o interés específico. A partir de la comprensión del concepto 'slum', elaborado por el programa de asentamientos humanos de las Naciones Unidas UNHabitat que lo define como una zona urbana densamente poblada caracterizada por viviendas de calidad inferior y miseria, se puede conceptualizar la actividad de slumming como una experiencia turística en áreas urbanas caracterizadas por la pobreza, miseria y violencia (Dürr \& Jaffe, 2012, p. 114).

Territorio informal, slum o invasión son palabras utilizadas frecuentemente como sinónimos y que generan un dilema conceptual; sin embargo, las tres palabras representan procesos y fenómenos diferentes.

Dovey \& King (2012) establecen la diferencia entre los tres conceptos: un territorio slum es una zona con deficiencias sanitarias y de vivienda; una invasión se refiere a los derechos en la tenencia de la tierra; y el asentamiento informal se refiere a prácticas que se salen del control estatal, se incluye dentro de esta, tanto actividades económicas como asentamientos fuera de la ciudad planeada.

A partir de lo anterior se decidió analizar esta variable desde el concepto de territorio informal, el cual permite incluir allí procesos más amplios que las deficiencias sanitarias y de vivienda que caracterizan un territorio slum.

Desde el análisis conceptual y teórico el slum tourism se describe como una forma alternativa de turismo construido sobre las tendencias de turismo de experiencias y propoor tourism o turismo a favor de los pobres, es una práctica turística que se aleja del enfoque económico-materialista del turismo.

Una vez ubicada espacialmente esta práctica turística en un contexto urbano específico, diversas disciplinas han trabajado alrededor de este fenómeno cuya discusión se ha enmarcado en diferentes abordajes conceptuales. Uno de ellos a partir del análisis de casos de estudio principalmente donde se originó esta práctica turística como son los asentamientos de Sudáfrica y el turismo de favelas en Brasil (Frenzel \& Koenz, 2012), la característica común en ambos casos es la historia de pobreza y violencia que representan y sobre la cual se desarrolla la práctica turística.

Otro abordaje es el planteado por Urry (2004), quien anota que para el turista contemporáneo cualquier cosa se convierte en una atracción, solo es necesario que territarias 39

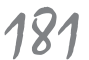


alguien la recomiende a otro algo que justifique ser visto o visitado. De esta forma, los sitios de pobreza o territorios de poblamiento informal como las favelas se han convertido en algo digno de ver como consecuencia de un acontecimiento o persona que induce esa mirada del turista hacia ellos.

El paisaje que representan estos lugares de poblamiento informal atrae la mirada del turista debido a la combinación de dos variables planteadas por Dovey \& King (2012): lo bello y estetíco, representado en sus formas y técnicas constructivas tradicionales y de alguna forma vernaculas, $y$ lo sublime, que representa la combinación entre ansiedad y placer experimentada en el encuentro con algo (una realidad, un espacio) abrumador y amenazante, pero en condiciones de seguridad.

El paisaje de estos lugares es una expresión de la cultura y su forma visible se manifiesta en la vida cotidiana de aquellos observados, sus creencias y costumbres. La forma en la que observan y lo que observan los turistas está asociada con la complejidad de la percepción visual y, por tanto, la contemplación se convierte en la base de la percepción. Los turistas no ven las cosas bajo la literalidad, sino que observan los objetos como señales y el discurso que hay detrás de estos, lo que se les dice que están observando. De esta forma, construyen la percepción del paisaje observado en los territorios de poblamiento informal.

\section{Metodología}

La investigación es de carácter descriptivo con un enfoque mixto, ya que las variables estudiadas tienen naturaleza cuantitativa y cualitativa. Se realizó mediante un trabajo de campo en zonas objeto de trasformaciones urbanas, asociadas con los procesos de ordenamiento territorial de la ciudad.

En el trabajo de campo se aplicaron encuestas a visitantes nacionales y extranjeros durante los meses de septiembre a noviembre del año 2015. El cuestionario se diseñó en dos idiomas (inglés y español) y fue realizado de manera dirigida y anónima. Se realizó un muestreo aleatorio simple sistemático, para población flotante, con un tamaño de muestra de 384 turistas, con una confiabilidad del $95 \%$ y un error del $5 \%$, aplicando la fórmula de población infinita.

Previamente, se aplicó una prueba piloto de 35 encuestas en dos zonas (Comuna 1: Metro cable - Santo Domingo y Comuna 13: Escaleras eléctricas) para ajustar preguntas, identificar el perfil del encuestador y evitar sesgos.

Las variables se identificaron a partir de algunos de los elementos que condicionan la percepción social y estética del visitante como son experiencias previas, interacción con el paisaje y aspiraciones. Estas se midieron mediante escalas cuantitativas de 1 a 5 , preguntas sí/no y preguntas abiertas. Las variables utilizadas fueron:

La información recogida por medio de la encuesta electrónica se exportó a un archivo local de formato Excel en el cual 
Tabla 1. Variables de la investigación

\begin{tabular}{|l|l|}
\hline \multicolumn{1}{|c|}{ Variable } & \multicolumn{1}{c|}{ Definición } \\
\hline Sociodemográficas. & Características del visitante. \\
\hline Interacción con la población local. & $\begin{array}{l}\text { Relaciones comerciales y comunicacionales que establece el } \\
\text { visitante con el residente. }\end{array}$ \\
\hline Experiencia previa en territorios informales. & Visitas previas a territorios de similares características. \\
\hline Actitud de la población. & $\begin{array}{l}\text { Percepción que tiene el visitante frente al comportamiento y } \\
\text { la forma de actuar de la población local. }\end{array}$ \\
\hline Experiencia en la zona. & $\begin{array}{l}\text { Es el resultado de las expectativas del visitante frente a las } \\
\text { actividades realizadas, interacción y actitud de la población } \\
\text { local. Es el último paso en la percepción del paisaje. }\end{array}$ \\
\hline
\end{tabular}

Fuente: elaboración propia.

se realizaron algunos de los procesos de tratamiento de datos.

Para el análisis inferencial de las variables de tipo cualitativo se utilizó el paquete estadístico Stat Graphics Centurion, con el cual se realizó el test de $j i$ al cuadrado $\left(\mathrm{X}^{2}\right)$. Este contrasta los resultados observados en una investigación con un conjunto de resultados teóricos, estos últimos calculados bajo el supuesto de que las variables fueran independientes. La diferencia entre los resultados observados y esperados se resume en el valor que adopta el estadístico $\mathrm{X}^{2}$, el cual tiene asociado un valor $p$, por debajo del cual se acepta o rechaza la hipótesis de independencia de las variables (Bewick, Cheek \& Ball, 2004).

Las relaciones planteadas que permitieron rechazar la hipótesis de independencia fueron entre las siguientes parejas de variables: procedencia y experiencias previas en territorios informales, relación comunicacional y relación comercial, actitud de la población y evaluación de la experiencia del turista.

\section{Apuntes sobre la ubicación de Medellín y el contexto de la transformación urbana}

Medellín es la segunda ciudad más poblada de Colombia, y hace parte de una conurbación llamada Valle de Aburrá, compuesta por diez municipios que conjuntamente tienen una población de 3550000 habitantes. Es el municipio más grande de este valle en términos de población con 2343049 habitantes, según cifras del censo de población y proyecciones municipales del Dane, 2010 (Alcaldía de Medellín - Empresa de Desarrollo Urbano EDU, 2014).

En Medellín el ritmo de urbanización durante la segunda mitad del siglo Xx sobrepasó la capacidad del Estado de proveer soluciones habitacionales planificadas y a esto se adicionaron otras problemáticas 
que existían en la ciudad como la violencia urbana y el narcotráfico en los años ochenta, así como el afianzamiento del crimen organizado lo que generó una brecha social en algunos territorios de la ciudad (Alcaldía de Medellín - Empresa de Desarrollo Urbano EDU, 2014).

La política urbana de Medellín a partir del año 2006 se fundamentó en un discurso orientado a cerrar las profundas brechas sociales de la ciudad, este discurso provenía de un movimiento político diferente y nuevo, ajeno a la estructura de parti- dos políticos liberal o conservador a los que tradicionalmente pertenecían quienes llegaban a la Alcaldía (Quinchía, 2013) y se convirtió en un modelo de ciudad denominado urbanismo social.

El urbanismo social surge como practica discursiva, y tal como lo concluye Montoya (2014), este discurso hace parte del ejercicio de la función pública de la ordenación del territorio, el cual contempla lógicas profundamente dialécticas, de manera que este discurso del urbanismo social no responde a intereses centrados en exclusivo

Figura 1. Ubicación de Medellín en el Valle de Aburrá

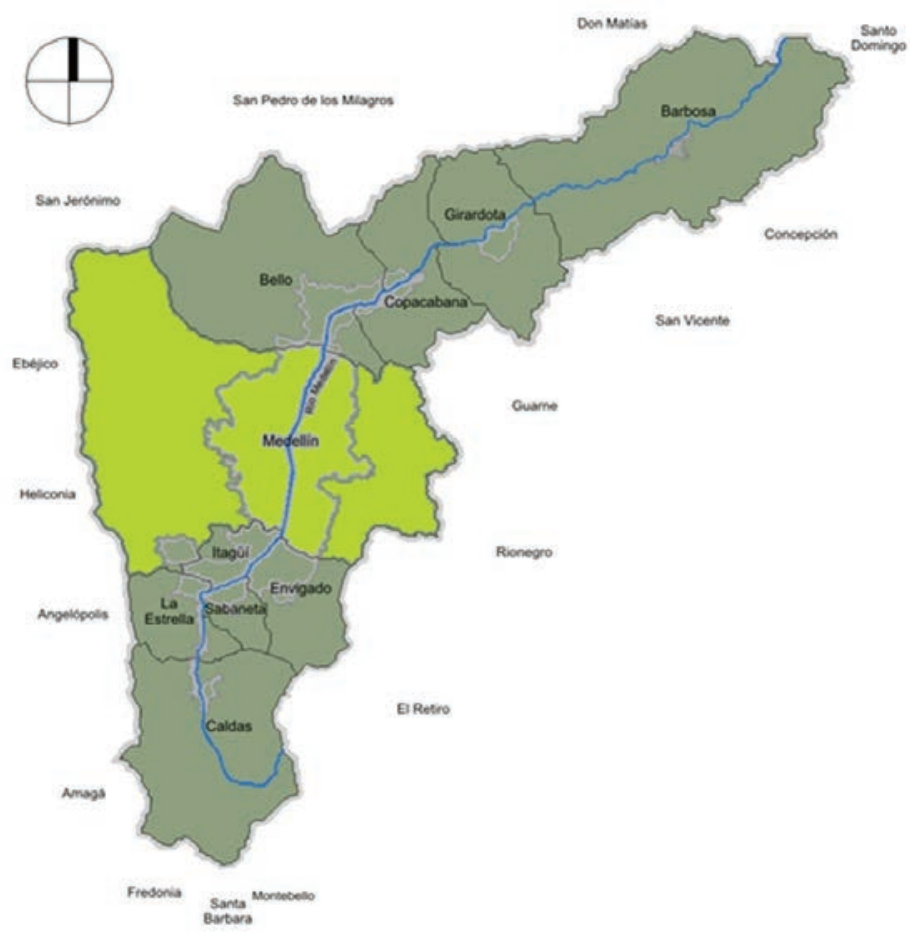

Fuente: elaboración propia con base en Rojas (2007). 
en lo social, como se predica, sino que está dirigido también a cambiar la imagen de la ciudad para hacerla un destino competitivo para inversionistas y turistas.

Desde la expedición de la Ley 388 de 1997 — Ley de desarrollo territorial—, el municipio de Medellín ha expedido tres acuerdos mediante los cuales adopta el plan de ordenamiento territorial POT. La continuidad en las políticas de ordenación territorial es lo que le ha otorgado ese título de ciudad que se transforma. Una ciudad que pasó de ser la más violenta del mundo a figurar hoy en medios internacionales por sus noticias positivas de procesos de cambio y transformación.

Lo anterior ha generado que la ciudad sea vista como un nuevo destino turístico urbano, actualmente Medellín es la tercera ciudad en la recepción de visitantes extranjeros en Colombia. Según estadísticas del Ministerio de Comercio, Industria y Turismo, ingresaron a la ciudad 280013 extranjeros durante el 2015 y una tasa de crecimiento en la llegada de turistas internacionales de $38,7 \%$ que la ubica como la ciudad con mayor crecimiento acumulado por concepto de turismo receptivo (Migración Colombia - Calculos OEE - Mincit, 2016).

El turismo llegó a esta ciudad como una consecuencia de diversas actuaciones urbanas, sociales y económicas y una apuesta desde la administración municipal por la consolidación de Medellín como destino de negocios, ferias y convenciones. La ciudad desarrolló una enorme estrategia de marketing urbano a partir del discurso inicial del urbanismo social.

\subsection{Presentación de las zonas de estudio}

Las cuatro zonas en las cuales se realizó la investigación han sido impactadas por actuaciones urbanas propuestas y ejecutadas desde los acuerdos que adoptan el Plan de Ordenamiento Territorial (POT) de Medellín (Acuerdo 062 de 1999 y Acuerdo 46 de 2006), dichas zonas han sufrido procesos de transformación urbana y fueron seleccionadas a partir de la revisión de la normativa territorial y los nuevos proyectos de ciudad que han tenido incidencia en el turismo, trabajo de campo y entrevistas con el personal que labora en los puntos de información turística (PIT) de Medellín sobre los lugares de la ciudad más solicitados por los turistas.

Las cuatro zonas de trabajo poseen la característica común de haber sido objeto de transformación urbana liderada por el gobierno local como parte de la estrategia de transformación de ciudad. Las zonas de trabajo se presentan en la figura 2 y son: Metrocable Santo Domingo y zona de influencia en la Comuna 1, Escaleras eléctricas en la Comuna 13, Metrocable Arví en su área de influencia en la estación el Tambo del Corregimiento de Santa Elena y Carabobo Norte.

Dos de estos territorios son considerados zonas de urbanización informal (Metrocable Santo Domingo y zona de influencia en la comuna 1 y Escaleras eléctricas Comuna 13) donde la práctica de slum tourism se visualiza como una nueva forma de territorialidad por parte de un territarias 39

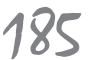




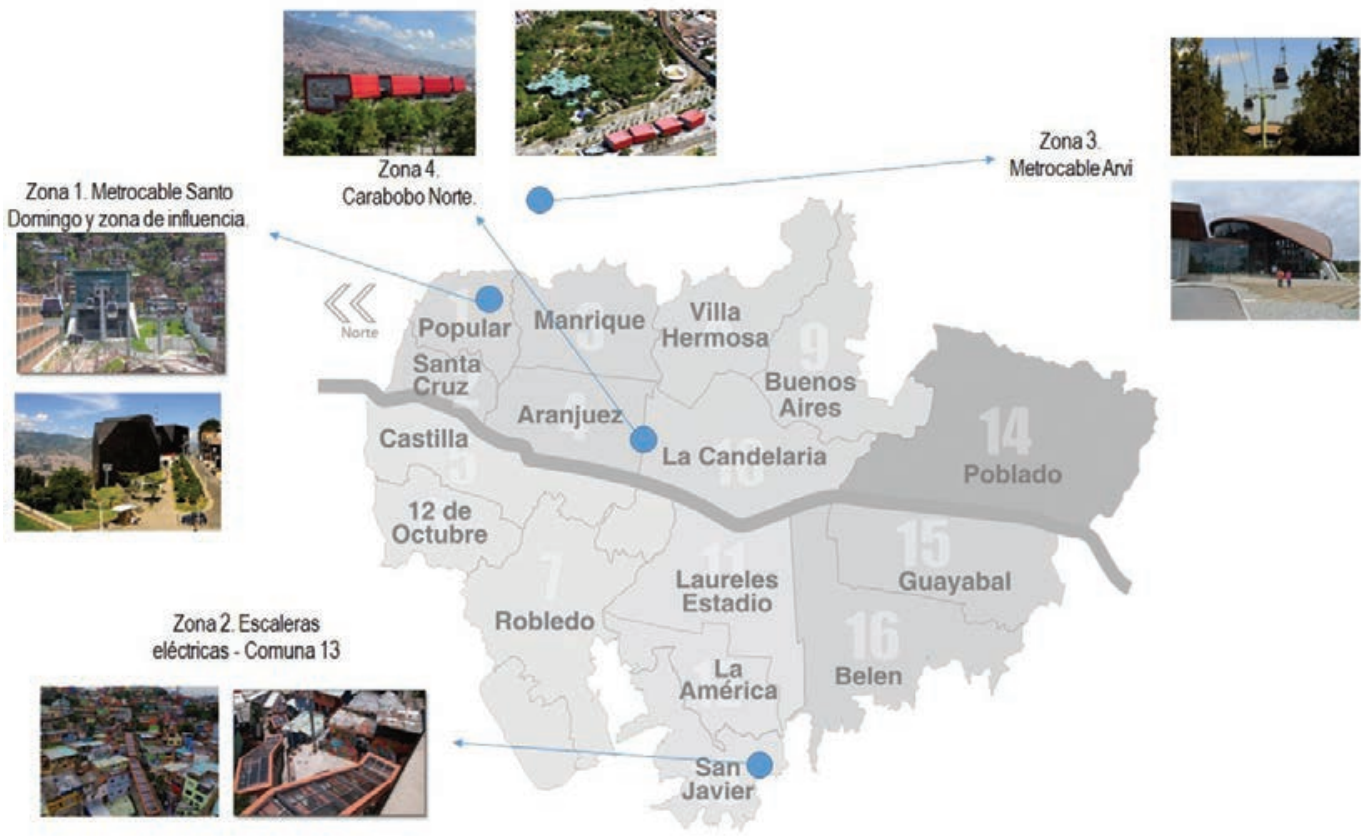

Fuente: elaboración propia con base en datos de la Alcaldía de Medellín.

actor otrora desconocido para estas poblaciones como lo es el turista.

El tercer territorio se caracteriza por ser una zona de transición urbano-rural (Metrocable Arví) intervenida para darle soporte a la estrategia de turismo de naturaleza de la ciudad. El último territorio es una zona de renovación urbana (Carabobo Norte) contemplada en los planes de ordenamiento territorial como la centralidad de la zona norte la cual cumple la función de dotar a la ciudad de nuevos equipamientos recreativos y culturales. territarios 39 186

\subsubsection{Metrocable Santo Domingo y} zona de influencia en la Comuna 1

El proceso de poblamiento del Barrio Santo Domingo se realizó vía loteo e invasión de personas y fue considerado un asentamiento subnormal hasta 1993 cuando mediante el Decreto 997 se realiza una ampliación del perímetro urbano.

En el periodo 2004-2007 la Comuna 1 fue una de las principales beneficiarias de los proyectos estratégicos de Medellín, debido a que cumplía con las características del urbanismo social; discurso que predominaba en los dirigentes locales del 
momento. Estas características eran: indicadores bajos de calidad de vida y desarrollo humano y presencia de bandas, milicias y autodefensas en conflicto mutuo (Cardenas, 2006).

El Proyecto Urbano Integral de la zona Nororiental (PUI Nororiental) tuvo una inversión de 16669 millones, aproximadamente, según el informe de proyectos estratégicos de la administración municipal del momento, en más de nueve obras de intervención física que se realizaron en la zona en un periodo de cuatro años, entre ellas, el sistema de transporte masivo por cable, obras de infraestructura para mitigar el amplio déficit de espacio público para la recreación, el encuentro y el esparcimiento (Cárdenas, 2006, p. 33), el parque biblioteca España, varios parques alrededor de las estaciones, el paseo urbano de la calle 106, el paseo Puerto Rico, parques miradores, adecuación de colegios y jardines infantiles, así como una mayor presencia institucional con la casa de Gobierno y el Centro de Desarrollo Empresarial Zonal (CEDezo) de Santo Domingo.

Todas estas intervenciones generaron en la zona nuevas dinámicas comerciales y la llegada de turistas comenzó a ser evidente a partir de la entrada en operación del metrocable en agosto de 2004 y la inauguración del parque Biblioteca en marzo de 2007.

\subsubsection{Escaleras eléctricas Comuna 13}

Están ubicadas en el barrio las Independencias I de la Comuna 13 de Medellín.
El proceso de poblamiento de este barrio comenzó con procesos de invasión de parte de familias desplazadas por la violencia en el campo en las fincas que existían en el occidente de Medellín y continuó con la construcción desordenada de asentamientos en la montaña, sin adecuada planeación, al menos para un sistema de acueducto y alcantarillado (Baracaldo, 2013).

Una zona marcada por la violencia y guerra urbana durante la década del noventa cuando "los grupos armados al margen de la ley alcanzaron una gran expansión y se apropiaron de la justicia y el problema se convirtió en una situación de orden nacional". (Departamento Administrativo de Planeación Municipal - Unión Temporal Plan de desarrollo Comuna 13, 2009, p. 31).

La idea de construir unas escaleras eléctricas al aire libre surge en agosto de 2004 , inspiradas en las escaleras eléctricas de varios lugares del mundo que se utilizan con fines turísticos como las del parque Guell y Montjuïc en Barcelona. Este proyecto se incorporó al proyecto urbano integral de la Comuna 13 (PUI) en agosto de 2006 con el nombre de Senderos de conexión Independencias I y se construyeron con el objetivo de solucionar los problemas de movilidad de las personas del sector, romper fronteras invisibles $y$ callejones de violencia.

Actualmente, esta zona es un referente para los turistas que llegan a la ciudad, figura como sitio de interés en la guía turística de Medellín y en portales de viajeros como tipadvisor con una propuesta de recorrido de memoria por la historia de la comuna a territarias 39

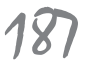


partir de la cultura hip-hop. Dichos recorridos son liderados principalmente por jóvenes del barrio agrupados en corporaciones culturales. También es una zona visitada por el turista de forma independiente o con agencias de viajes externas al territorio.

\subsubsection{Metrocable Arvi}

El territorio Arví comprende gran parte del corregimiento de Santa Elena de Medellín y otros municipios de Antioquia como Guarne, Envigado, Bello y Copacabana, es una zona clasificada como suelo rural y, por su cercanía al centro de la ciudad de Medellín, enfrenta procesos de transición rural-urbano.

El Metrocable Arví es un cable de uso turístico que conecta la zona urbana de Medellín con el territorio rural del corregimiento de Santa Elena. La zona de estudio para esta investigación es el área de influencia del Metrocable Arví en la estación el Tambo, la cual está ubicada estratégicamente en un nodo distribuidor de vías que conducen hasta el centro recreativo de Comfenalco, la laguna de Guarne, la Vereda Mazo y la autopista Medellín - Bogotá. (Subsecretaría de transporte y tránsito, Subsecretaría ténica - Municipio de Medellín, 2008).

Este cable hace parte del megaproyecto parque Arví, el cual fue concebido inicialmente como un proyecto ambiental con leves orientaciones hacia el turismo. En la actualidad opera como parque gracias a la construcción y adecuación de equipamientos y la administración de la Corpo- ración Parque Arví. Las transformaciones territoriales incidieron en las dinámicas de la zona convirtiéndola en un sitio de recreo y esparcimiento para la población urbana de Medellín y un sitio obligado de visita para los turistas que llegan a la ciudad.

\subsubsection{Carabobo Norte}

La zona de Carabobo Norte está localizada en la Comuna 4, Aranjuez, es un sector con importantes puntos de interés turístico, que además son lugares de encuentro tanto a escala comunal como en el ámbito de ciudad.

Desde el РОт de 1999 se le asigna el tratamiento de redesarrollo a la zona, lo cual significa que es una zona con buena capacidad instalada pero que requiere reforzar la tendencia en el uso y el aprovechamiento con mayor intensidad, por tanto, este tratamiento busca una consolidación urbanística por medio de nuevas dotaciones en la infraestructura, el espacio público y el equipamiento colectivo (Departamento Administrativo de Planeación - Universidad Nacional de Colombia, 2003).

Para la década del 2000 se dieron las mayores transformaciones en la zona. Actualmente la zona norte de Medellín es considerada como el distrito de la innovación debido a la continuidad en el proceso de renovación urbana iniciado desde el año 2002. Allí se localizan importantes equipamientos culturales que hacen parte a su vez de los atractivos culturales de la ciudad como el Parque Explora, el Jardín Botánico, el Planetario, el Parque de los Deseos, el Centro Cultural de Moravia, entre otros. 
Figura 3. Tipo de turistas por zona

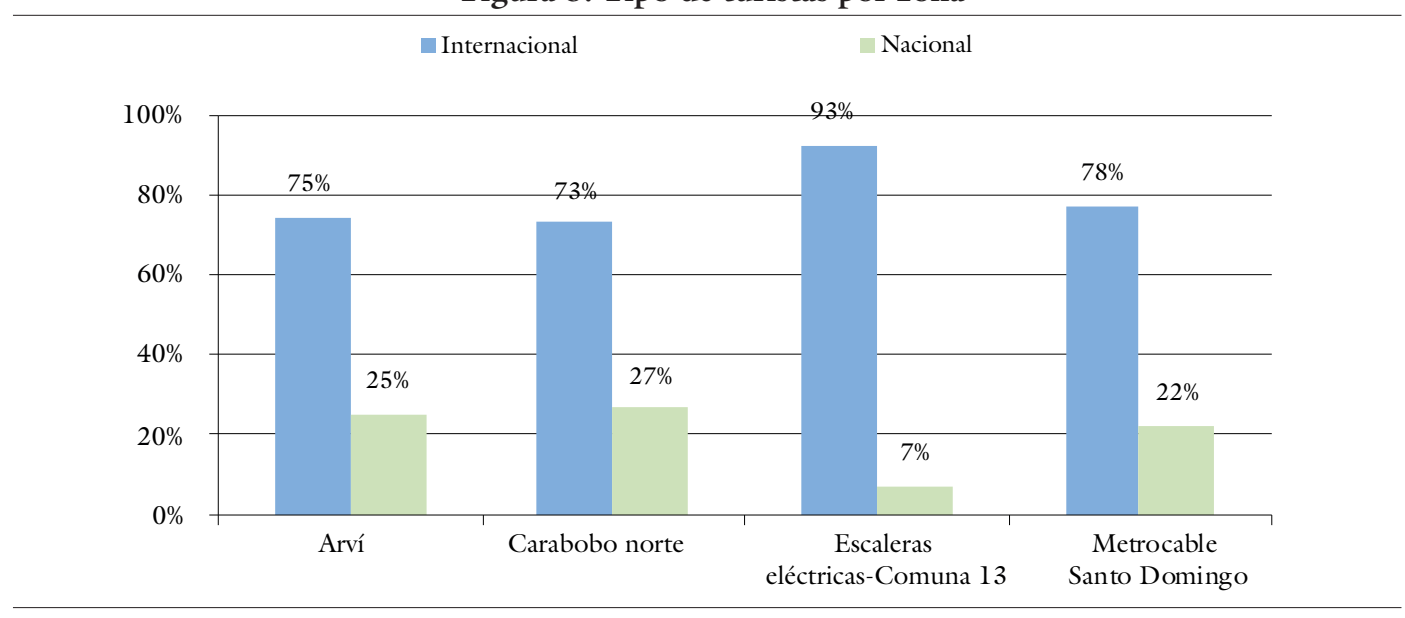

Fuente: elaboración propia.

Figura 4. Procedencia de turistas internacionales por zonas

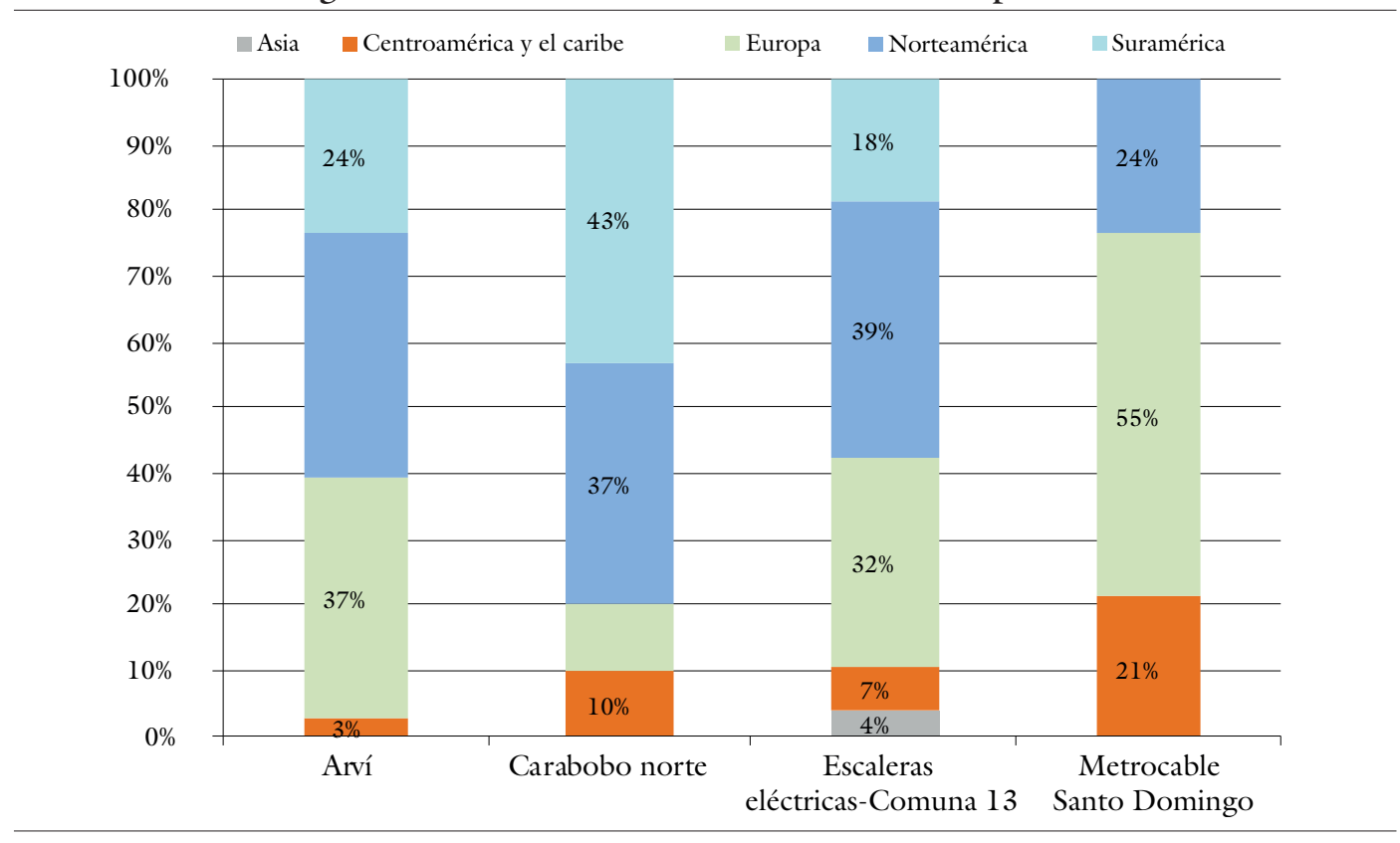

Fuente: elaboración propia. 


\section{Resultados}

\subsection{Análisis descriptivo} de las variables investigadas

\subsubsection{Sociodemográficas}

Del total encuestado, el $49 \%$ de los visitantes fueron mujeres y el $51 \%$ fueron hombres. El $32 \%$ corresponde a visitantes nacionales y el $68 \%$ a internacionales, los cuales provienen principalmente de Norteamérica y de Europa con un porcentaje $35 \%$ y $34 \%$, respectivamente.

La figura 3 muestra el porcentaje de visitantes internacionales y nacionales por zona, donde se puede observar mayor porcentaje de visitantes internacionales en cada una de estas.

$\mathrm{Al}$ analizar la procedencia de visitantes internacionales por zona en la figura 4 , se encuentra que el mayor porcentaje en cada una de estas corresponde a norteamericanos y europeos a excepción de Carabobo Norte donde en su mayoría se encuestaron visitantes procedentes de Suramérica.

Por tanto, se concluye que son los visitantes procedentes de Europa y Norteamérica los que incluyen con mayor frecuencia dentro su viaje a Medellín la visita a las zonas periféricas, mientras la zona central como es Carabobo Norte recibe principalmente visitantes de Suramérica, Centroamérica y el Caribe.

\subsubsection{Experiencias previas en territorios informales}

Esta variable se analizó en dos zonas: Escaleras Eléctricas y Metrocable Santo Domingo, las cuales tienen características de territorio informal como ilegalidad e informalidad en la tenencia de la tierra e informalidad económica.

\section{territarias 39}

Figura 5. Experiencia previa en territorios informales por zonas

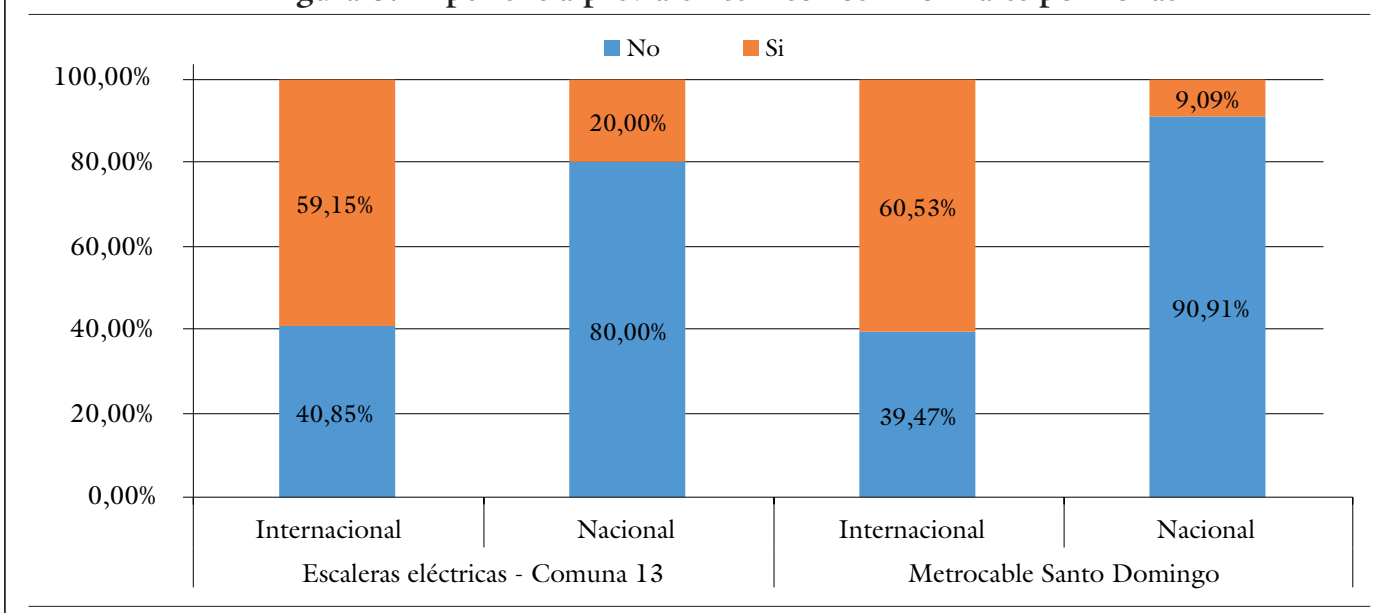

Fuente: elaboración propia. 
Los resultados de esta preguntan muestran que el $58 \%$ de los turistas internacionales encuestados afirman haber visitado territorios informales previamente, lo cual, dado el error de muestreo del $5 \%$, permite concluir que aproximadamente el $50 \%$ de los visitantes internacionales ha tenido experiencias previas en territorios informales. Caso contrario con los visitantes nacionales, de los cuales solo un porcentaje muy pequeño (10\%) lo ha hecho.

Cuando se hace el análisis por zonas, como se puede ver en la figura 5 , los visitantes internacionales en un porcentaje alto han tenido experiencias de este tipo.

La situación anteriormente expuesta no ocurre con los visitantes nacionales, va que en las zonas Escaleras Eléctricas, Comuna 13 y Metrocable Santo Domingo tan solo el $20 \%$ y $10 \%$, respectivamente, han tenido experiencias previas en territorios informales.

Al realizar la prueba de independencia entre las variables procedencia y experiencias en territorios informales (tabla 2), arroja un valor $P$ de 0,0001 , lo cual permite rechazar la hipótesis de independencia y concluir que el lugar de procedencia del visitante incide en que prefiera visitar o no territorios informales. Esta situación es congruente con la tesis planteada por Urry (2004) sobre el posturista, en la que se afirma que el posturista es el turista de la época posmoderna el cual en sus vacaciones busca una ruptura con sus formas

Figura 6. Países donde se han dado experiencias previas de turismo en territorios informales

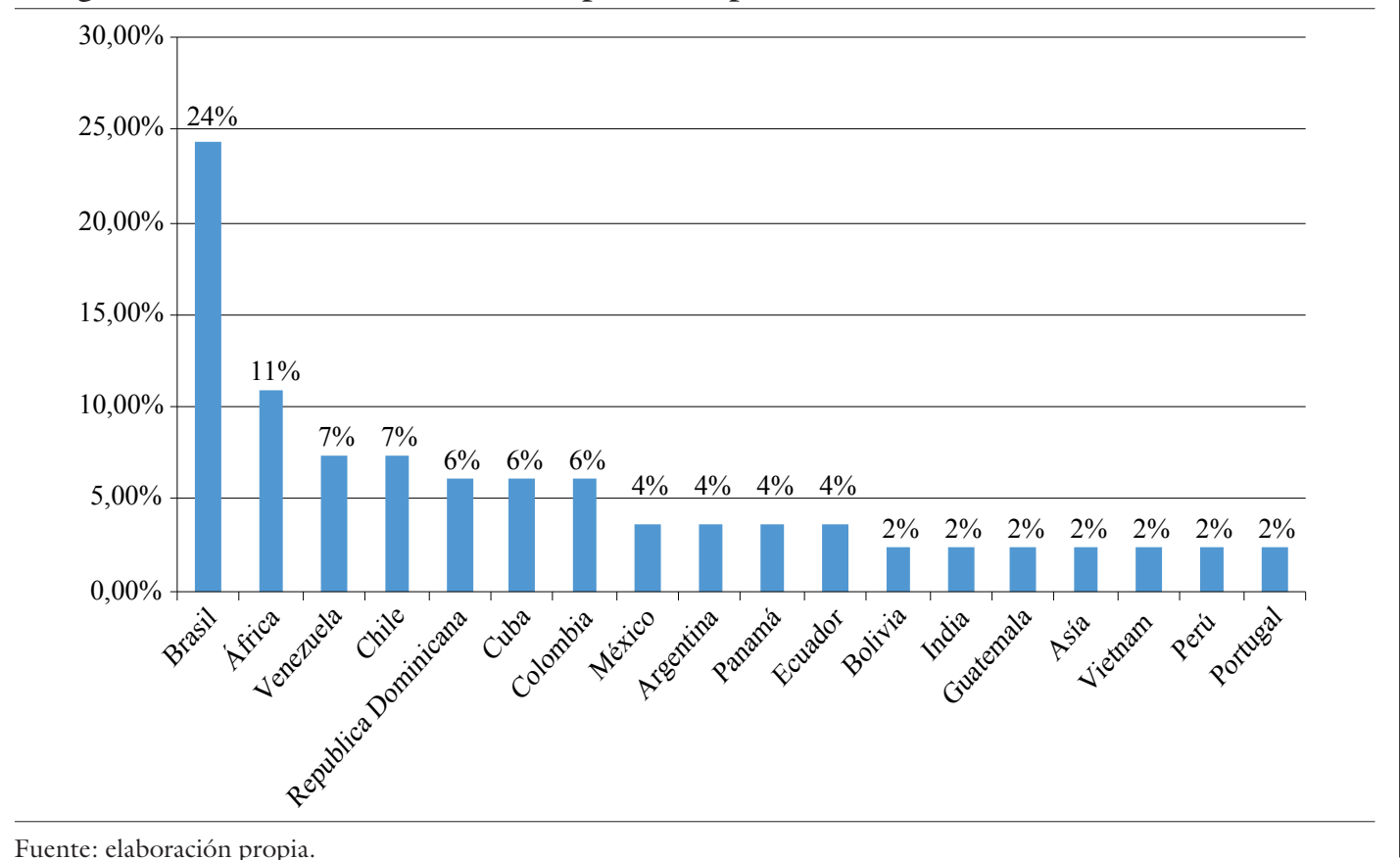


tradicionales de consumo durante su vida cotidiana, es decir, experiencias fuera de lo ordinario y es en este contexto donde se puede explicar el interés por visitar territorios de pobreza y poblamiento informal de los visitantes procedentes de Norteamérica y Europa y la consecuente turistificación de estos espacios.

Tabla 2. Prueba de independencia procedencia y experiencia en territorios informales

\begin{tabular}{|l|c|c|c|}
\hline \multirow{2}{*}{ Zona } & \multicolumn{3}{|c|}{ Prueba ji al cuadrado } \\
\cline { 2 - 4 } & Estadístico & G1 & Valor-P \\
\hline $\begin{array}{l}\text { Escaleras Eléctricas, } \\
\text { Comuna 13 }\end{array}$ & 2,915 & 1 & 0,0878 \\
\hline $\begin{array}{l}\text { Metrocable - Santo } \\
\text { Domingo }\end{array}$ & 9,031 & 1 & 0,0027 \\
\hline
\end{tabular}

Fuente: elaboración propia.

En cuanto a las experiencias previas, los países referenciados por los visitantes encuestados se concentran en su mayoría en Latinoamérica y el Caribe, seguido de países en África y, en menor medida, en el continente asiático. La figura 6 evidencia, para el caso de Latinoamérica y el Caribe, que los países más referenciados son Brasil, Venezuela, Chile, Republica Dominicana y Cuba.

La interacción del turista con la población local se analizó a partir de dos tipos: las comunicacionales y las comerciales.

Para esta pregunta se utilizó respuesta cerrada sí/no y se parte de la presunción de que no hay puntos intermedios en un proceso de interacción. Los resultados dan una idea inicial del consumo del paisaje que hace el visitante por medio de los procesos comunicacionales, lo que puede generar transformaciones en los hábitos y formas de vida del habitante local y su percepción frente al mundo.

Con respecto a la interacción comunicacional, el $62 \%$ de los turistas encuestados afirma haber establecido relaciones dialógicas con la comunidad. Al realizar el análisis por zona se observa que el turista internacional manifiesta haber tenido mayor interacción con la población local, en porcentajes de 76\% en Arví, 59\% en Carabobo Norte, 55 \% en Escaleras Eléctricas y $79 \%$ en Metrocable Santo Domingo.

En el caso de los nacionales se pueden observar porcentajes menores de interacción, en las zonas Arví (39\%), Carabobo Norte (36\%) y Metrocable Santo Domingo $(36 \%)$, pero en el caso de escaleras eléctricas se presenta un porcentaje alto de interacción similar al de los internacionales, en esta zona el consumo del paisaje tiene la particularidad de que gran parte de los visitantes que llegan allí lo hacen por medio del recorrido guiado liderado por diferentes operadores de turismo locales durante este, se incita al diálogo no solo con el guía que pertenece al territorio, sino con otras personas que se encuentran durante el recorrido y que hacen parte de la memoria histórica de este lugar.

El detalle se encuentra en la figura 7.

Las relaciones comerciales se midieron por medio del consumo de algún producto o servicio ofrecido por la población local. El $68 \%$ de todos los turistas encuestados en las zonas afirman haber consumido algo. 
Figura 7. Relaciones comunicacionales con la población local

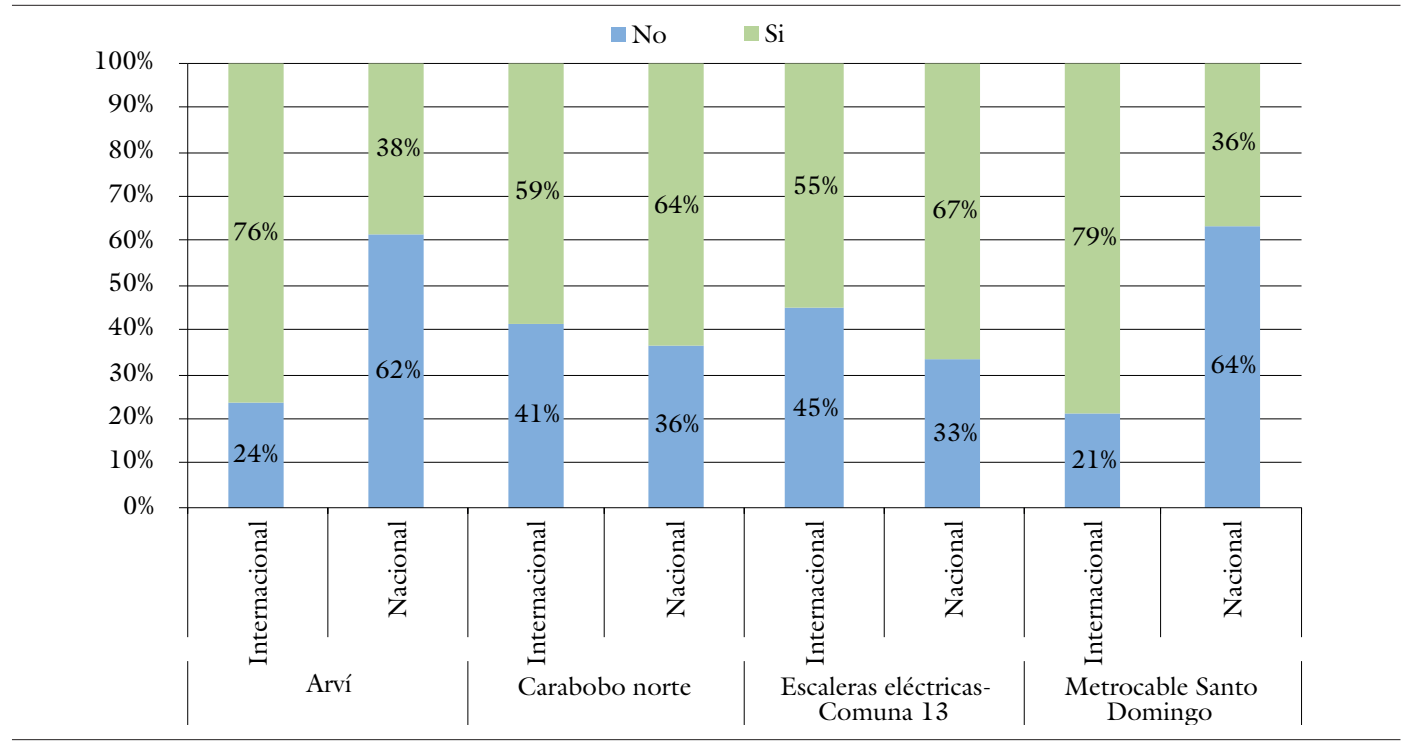

Fuente: elaboración propia.

Figura 8. Relaciones comerciales por zona

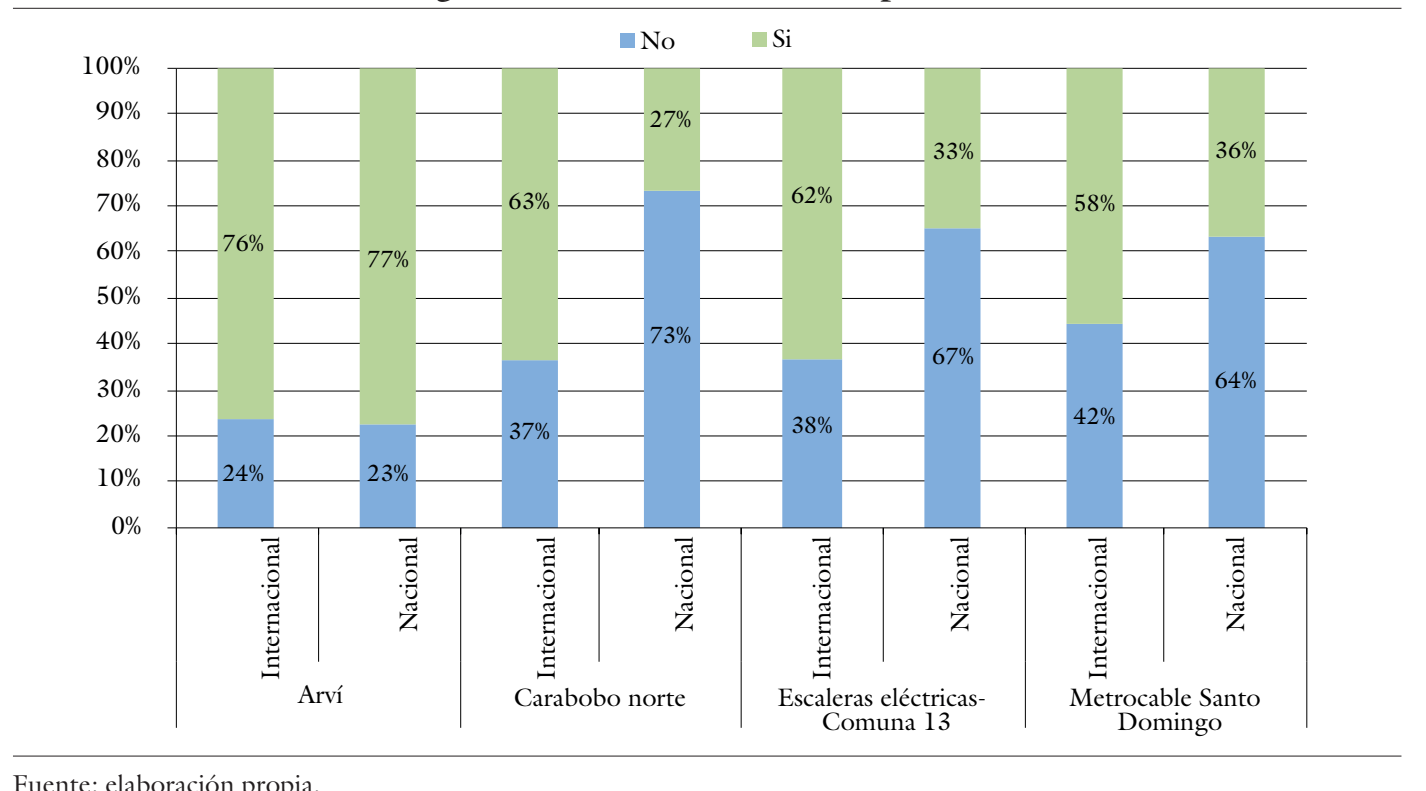

Fuente: elaboración propia. 


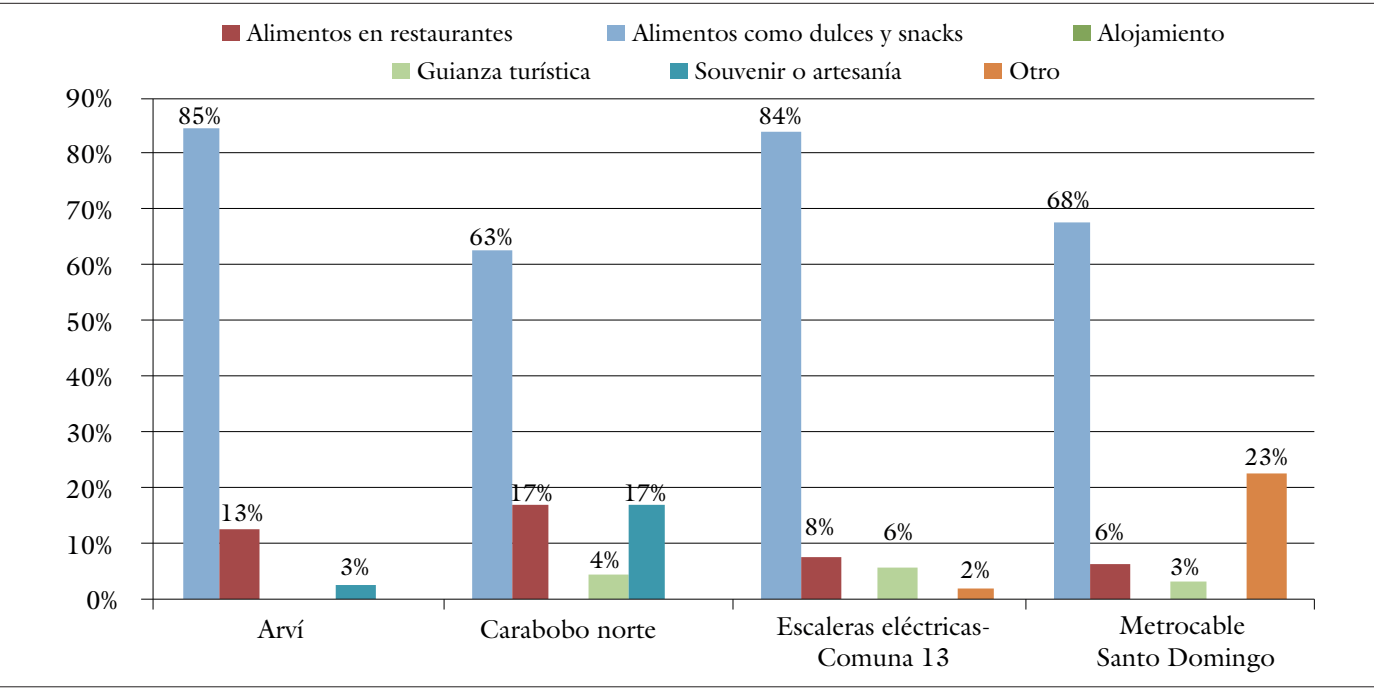

Fuente: elaboración propia.

En el análisis por zona se puede observar que Arví es la que presenta mayor consumo tanto de visitantes nacionales como internacionales con porcentajes $77 \%$ y $76 \%$, respectivamente, como se muestra en la figura 8. Esta situación se presenta por la oferta de productos gastronómicos y artesanales existentes con programas como mercados campesinos y ventas formales e informales. En las otras zonas el visitante internacional presenta porcentajes altos de consumo y el nacional presenta porcentajes menores.

$\mathrm{Al}$ analizar en detalle el tipo de consumo se encontró que la compra de alimentos como dulces y snacks predomina ampliamente mientras que la adquisición de suvenir y artesanías, así como la contratación de servicios de guianza, se da en porcentajes muy pequeños, además no contratan servicios de alojamiento en ninguna de las zo- nas (figura 9), a pesar de la oferta existente principalmente en la zona Arví.

Al realizar la prueba de independencia entre la relación comunicacional y comercial por zona se obtuvo un valor $P$ menor que 0,05 en casi todas las zonas, excepto en las escaleras eléctricas (tabla 3 ), lo que demuestra que el establecimiento de relaciones comerciales implica el establecimiento de relaciones comunicacionales. Se pudo establecer por medio de las preguntas cualitativas que para los visitantes el acto de comprar es un acto comunicacional.

En la zona escaleras eléctricas, Comuna 13 no hay relación entre las variables, al parecer los visitantes que compran productos no necesariamente establecen relaciones comunicacionales. El detalle se relaciona en la tabla 3 . 
Tabla 3. Prueba de independencia relaciones comerciales y comunicacionales

\begin{tabular}{|l|c|c|c|}
\hline \multirow{2}{*}{ Zona } & \multicolumn{3}{|c|}{ Prueba ji al cuadrado } \\
\cline { 2 - 5 } & Estadístico & G1 & Valor-P \\
\hline Arví & 17,654 & 1 & 0,0000 \\
\hline Carabobo Norte & 22,874 & 1 & 0,0000 \\
\hline $\begin{array}{l}\text { Escaleras eléctricas, } \\
\text { Comuna 13 }\end{array}$ & 2,540 & 1 & 0,1110 \\
\hline $\begin{array}{l}\text { Metrocable - Santo } \\
\text { Domingo }\end{array}$ & 18,682 & 1 & 0,0000 \\
\hline
\end{tabular}

Fuente: elaboración propia.

\subsubsection{Actitud de la población percibida por los turistas}

Esta variable hace parte del proceso evaluativo de la experiencia de percepción y para analizarla se utilizó la siguiente escala de valoración; excelente (5), sobresaliente (4), regular (3), mala (2), deficiente (1). A partir de esta escala se presentan los resultados.

Del total de los turistas encuestados en las zonas el $56 \%$ consideran que la actitud de la población fue excelente y el $14 \%$ afirman sobresaliente. Al analizar cada zona se tiene que los turistas perciben una mejor actitud de la población en la zona Escaleras Eléctricas, Comuna 13 y Arví con una valoración excelente del $74 \%$ y $61 \%$, respectivamente.

Al discriminar los resultados según procedencia del visitante se presentan diferencias en las valoraciones. En todas las zonas el visitante internacional valora como excelente la actitud de la población con porcentajes de $50 \%$ en Arví, $60 \%$ en
Carabobo Norte, 72 \% Escaleras Eléctricas, Comuna 13 y 68 \% Metrocable Santo Domingo. En el caso del visitante nacional hay una opinión divida, se presenta una valoración de excelente en las zonas Arví (92\%) y Escaleras Eléctricas, Comuna 13 (100\%), mientras que en las zonas Carabobo Norte y Metro cable Santo Domingo predomina una valoración regular con porcentajes del $64 \%$ y $73 \%$, respectivamente. Esto se evidencia en la figura 10.

Lo anterior permite concluir que hay diferencias entre la percepción del visitante internacional y nacional en lo relacionado con la actitud de la población en las zonas Carabobo Norte y Metrocable Santo Domingo, situación que amerita profundizar en los resultados a partir de análisis de percepción con métodos y técnicas cualitativas.

\subsubsection{Experiencia en la zona}

Esta variable recoge la valoración final de la percepción, en esta se utilizó la misma escala de valoración de la variable actitud de la población. El $70 \%$ valora entre excelente y sobresaliente su experiencia, el $27 \%$ como buena y el $2 \%$ como regular.

En el análisis por zona y procedencia de visitantes se presentan dos situaciones: la primera, cuando el visitante nacional e internacional evalúan la experiencia de la misma forma como en el caso de las zonas Arví, Escaleras Eléctricas, Comuna 13 y Carabobo Norte. El visitante internacional y nacional califican la experiencia como excelente en la zona Arví con porcentajes de $58 \%$ y $92 \%$ y Escaleras Eléctricas, Comuna 


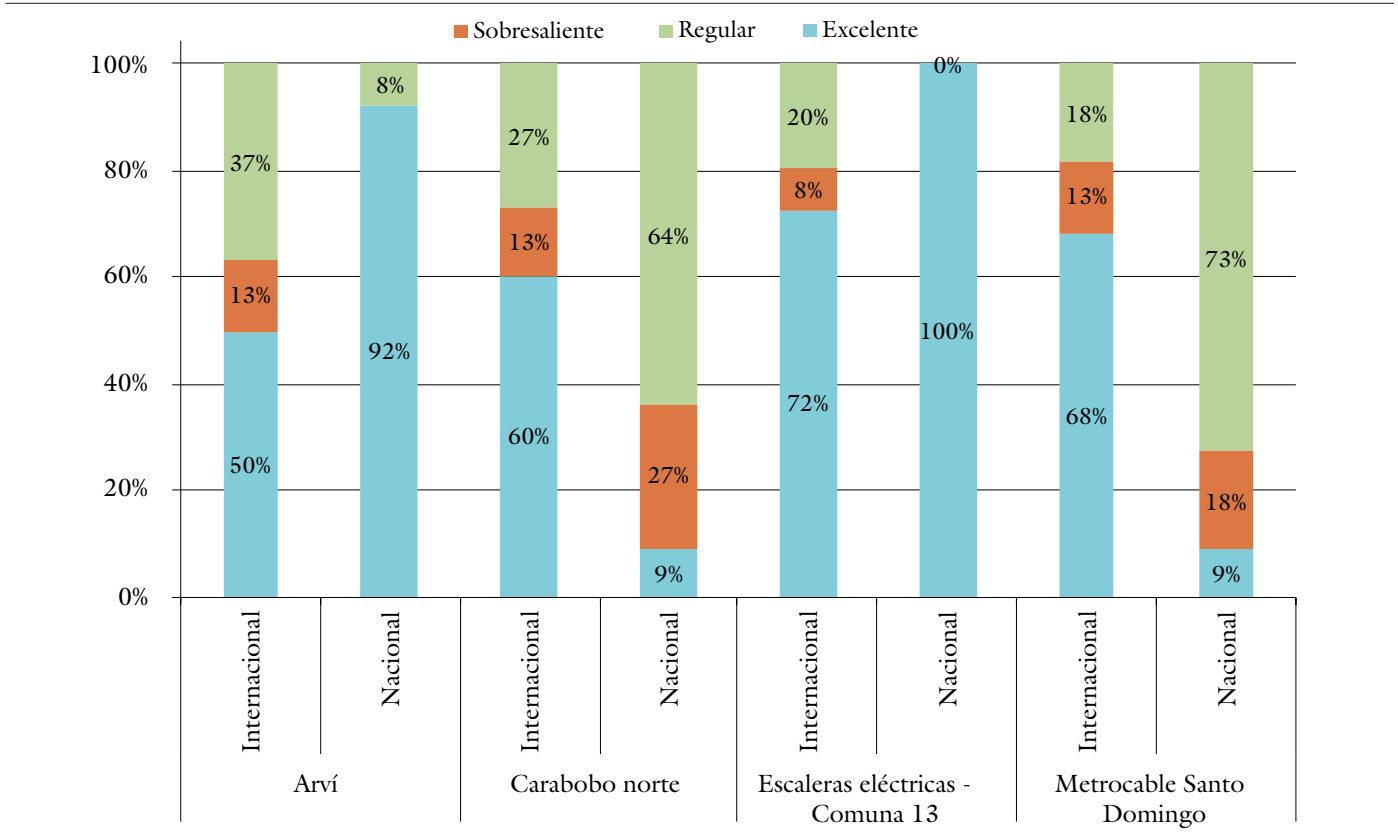

Fuente: elaboración propia.

13 con porcentajes de $76 \%$ y $100 \%$. En Carabobo Norte predomina la valoración regular de parte del visitante internacional y nacional con porcentajes de $67 \%$ y $73 \%$. Se concluye entonces que esta zona es la que presenta menor valoración tanto del visitante internacional como nacional.

La segunda situación se presenta cuando las valoraciones del turista nacional e internacional no coinciden como en la zona Metrocable Santo Domingo donde el visitante internacional valora su experiencia como excelente con un $61 \%$ y el visitante nacional como regular con un $73 \%$. No se pueden concluir las razones territarias 39 196 en ella, se requiere un estudio exploratorio complementario de tipo cualitativo para identificar las causas, las cuales pueden estar asociadas con el entorno inmediato del visitante que influye su proceso de valoración. Los detalles de estas situaciones se presentan en la figura 11 .

Frente a la valoración de esta variable llama la atención que la zona Metrocable Santo Domingo recibe la valoración más baja de todas las zonas de parte del visitante nacional.

Se realizó prueba de independencia entre las variables actitud de la población y evaluación de la experiencia del turista, con un valor $P(0,0000)$ se establece una 
Figura 11. Calificación de la experiencia en la zona

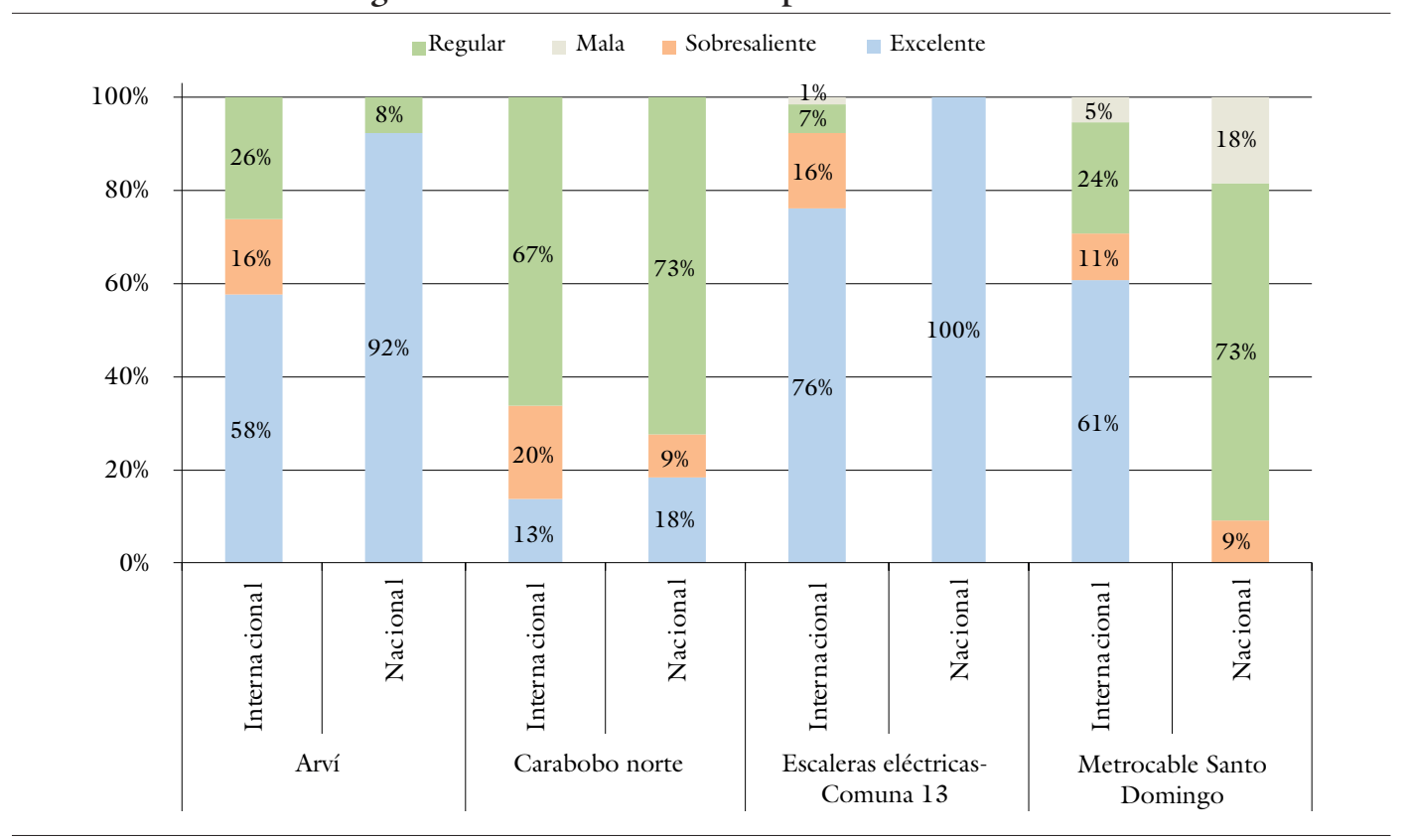

Fuente: elaboración propia.

relación entre ambas variables, esta condición persiste en el análisis zonal como se muestra en la tabla 4 .

Tabla 4. Relación entre las variables actitud de la población y evaluación de la experiencia del turista

\begin{tabular}{|l|c|c|c|}
\hline \multirow{2}{*}{\multicolumn{1}{|c|}{ Zona }} & \multicolumn{3}{c|}{ Prueba Ji-cuadrado } \\
\cline { 2 - 4 } & Estadístico & G1 & Valor-P \\
\hline Arví & 57,703 & 4 & 0,0000 \\
\hline Carabobo Norte & 23,260 & 4 & 0,0001 \\
\hline $\begin{array}{l}\text { Escaleras eléctricas, } \\
\text { Comuna 13 }\end{array}$ & 56,498 & 6 & 0,0000 \\
\hline $\begin{array}{l}\text { Metrocable - Santo } \\
\text { Domingo }\end{array}$ & 21,051 & 6 & 0,0018 \\
\hline
\end{tabular}

Fuente: elaboración propia.
A partir de la prueba de independencia se concluye que la actitud de la población incide en la valoración que el turista hace de su experiencia global en el territorio y, por tanto, confirma la tesis que la percepción del paisaje como recurso turístico es un ámbito que trasciende la experiencia físicoespacial y se introduce en temas de desarrollo local y participación comunitaria que requieren mayor incidencia de la población local en la gestión del turismo en estos territorios.

\section{Conclusiones}

Como se mencionó en el aporte teórico, la percepción es una construcción subjetiva territarias 39 
y sesgada de una realidad; sin embargo, es necesario operacionalizar este concepto por medio de algunas variables que ayuden a construir una evaluación de los lugares visitados como resultado de la experiencia sensorial. Este tipo de estudios para conocer cómo percibe el visitante los lugares visitados, y en los cuales la práctica turística es de reciente inclusión, son fundamentales para plantear estrategias de base local que fortalezcan la vocación turística de estos espacios y para planificar y desarrollar la actividad dentro de los principios de sostenibilidad.

Por tratarse de un estudio descriptivo, considerada una estrategia de primer nivel en la investigación y debido a la técnica (encuesta) y el instrumento seleccionado (cuestionario), algunas variables y sus resultados requieren ser profundizadas contemplando métodos y técnicas cualitativas que permitan dar respuestas sobre causas o razones de los hechos que se observan y llaman la atención de los investigadores, como por ejemplo la diferencia en la percepción de la actitud de la población y la evaluación de la experiencia entre los diferentes segmentos de turistas (nacionales e internacionales).

Los principales resultados de esta investigación demuestran que los turistas internacionales tienen mayor experiencia visitando territorios informales, lo que se concibe como una posible motivación de este al momento de viajar hacia Medellín y hacer recorridos por los barrios de poblamiento informal como Santo Domingo y el barrio las Independencias en la
Comuna 13. Estos territorios informales en Medellín son visitados principalmente por europeos y norteamericanos como se evidencia en la figura 4.

El consumo que realizan los visitantes en estos espacios se limita principalmente a la compra de alimentos como dulces y snacks. La venta de suvenirs como artesanías es una estrategia que se podría implementar en los territorios informales y que serviría mucho a la comunidad, así como también la contratación de servicios de guianza. De igual manera, el servicio de alojamiento es un tema que se podría pensar en el futuro tal y como se hace en las favelas de Río de Janeiro con los turistas que buscan tener experiencias cercanas con la población local.

La interacción de los turistas con la población local es un elemento clave para garantizar la sostenibilidad del paisaje como recurso turístico y la sostenibilidad de la actividad en estos territorios, dicha interacción debe superar el simple acto comercial y trascender al establecimiento de relaciones dialógicas igualitarias entre anfitriones y visitantes, lo cual ayudaría a ampliar el horizonte cultural de ambos grupos y aportaría a la aceptación de la práctica turística por parte de la población local principalmente en los territorios tipificados en esta investigación como de poblamiento informal.

En el análisis según procedencia del visitante se concluye que es el visitante internacional quien presenta mayores niveles de interacción con la población local, es decir, establece mayores diálogos 
con los habitantes y consume con mayor frecuencia productos y servicios ofrecidos por la población local. De igual manera, es el visitante internacional el que valora la actitud de la población como excelente en todas las zonas.

Llama la atención la situación que se presenta con la zona metrocable Santo Domingo, la cual fue la primera intervención en un barrio informal que atrajo la mirada de los turistas, con los resultados de esta investigación y el trabajo de campo realizado por los investigadores se evidencia que la zona presenta un declive en llegada de turistas, son pocos los que descienden en esta estación y realizan un recorrido por la zona, situación que antes era común. Así mismo, resalta la valoración de regular que hace el visitante nacional sobre su experiencia en la zona. Posibles explicaciones para este declive son primero, la entrada en operación del cable turístico Arví que se conecta con la estación Santo Domingo, por lo cual los turistas no descienden en esta estación, sino que continúan su recorrido hacia el parque Arví; segundo, el surgimiento de nuevas zonas de turismo en la ciudad con características ; y tercero, el deterioro del parque Biblioteca España el cual era uno de los principales atractivos en este sector de la ciudad.

Por otro lado, la experiencia del turista en la zona Escaleras eléctricas en la Comuna 13 fue valorada de manera excelente tanto por los turistas nacionales como internacionales. Situación que se presenta quizá por el grado de desarrollo turístico que ha alcanzado este espacio de la ciudad en los últimos años, generado por la participación de diferentes actores comunitarios, organizaciones culturales y operadores turísticos y por diferentes estrategias de marketing de transformación territorial ligadas a las expresiones estéticas del grafiti y la resiliencia social del territorio luego de la violencia experimentada años atrás en la comuna y donde hoy es posible evidenciar practicas turísticas con enfoque cultural.

Otra zona que requiere una mirada especial es el sector de Carabobo Norte, está consolidada como de turismo para la ciudad con los mayores equipamientos recreativos y culturales, allí la calificación de la experiencia para ambos tipos de público (nacionales e internacionales) fue regular, situación que requiere profundizarse en futuras investigaciones a partir de un análisis de los elementos que el turista utiliza para emitir un juicio sobre su experiencia, y que la ciudad debe analizar de cara a futuras estrategias de gestión de turismo en la zona.

Si bien, la actitud de la población condiciona la experiencia del visitante, no es el único elemento a tener en cuenta al momento del turista valorar su experiencia global. Esto se evidencia en la zona Carabobo Norte donde el turista internacional valora la actitud de la población, principalmente como excelente; sin embargo, la calificación de la experiencia fue evaluada como regular por la mayoría de los encuestados.

Con los procesos de transformación urbana que Medellín está realizando en los barrios de poblamiento informal, la ten- territarias 39

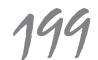


dencia de slum tourism es un segmento que la ciudad debe comenzar a pensar y planear a partir de análisis de casos comparativos con otros países con mayor experiencia en este tipo de visitas como Brasil, con el fin de consolidar este segmento como una verdadera apuesta comunitaria y no a merced del mercado de los operadores turísticos externos.

La transformación urbana que ha experimentado la ciudad de Medellín es una oportunidad para el turismo; sin embargo, desde la observación y el trabajo de campo en la práctica turística que se evidencia en estos territorios de Medellín, la interacción entre turistas y residentes está dada principalmente por el consumo de algún producto o servicio, donde el nivel de involucramiento de la comunidad se limita a las relaciones comerciales como complemento al sistema de movilidad. Los flujos turísticos son direccionados desde el discurso de la administración local por medio de la estrategia de marketing territorial y no por la existencia de un producto turístico consolidado.

Por lo anterior, la ciudad requiere trabajar de la mano con operadores turísticos y comunidad local de cada sector de transformación urbana para que el turismo actúe también como una estrategia de transformación económica y social.

Finalmente, la percepción del paisaje y la valoración de la experiencia es un concepto subjetivo que depende del entorno social y cultural de quien emite el juicio. Por tanto, es natural que visitantes nacionales e internacionales tengan valoraciones diferentes. Por otro lado, esta investigación solo indagó algunos aspectos sobre la percepción del visitante y quedan temas de estudio pendientes, como los motivos que impulsan a estas personas a visitar principalmente territorios de poblamiento informal.

\section{Referencias}

Alcaldía de Medellín - Empresa de Desarrollo Urbano EDU. (2014). Medellín modelo de transformación urbana. Medellín: Alcaldía de Medellín - Empresa de Desarrollo Urbano EDU.

Arango, S. (2009). Las ciudades de negocios en las megaciudades latinoamericanas. En P. Brand, La Ciudad Latinoamericana en el Siglo XXI. Globalización, neoliberalismo, planeación (pp. 247 257). Medellín: Universidad Nacional de Colombia.

Baracaldo, D. (9 de abril de 2013). El hombre que sembró una escalera eléctrica en la Comuna 13. Kienyke. Recuperado de https://www.kienyke.com/historias/ cesar-hernandez-construyo-escaleraselectricas-en-la-comuna- 13

Bewick, V., Cheek, L., \& Ball, J. (2004). Statistics review 12: Survival analysis. Critical Care, 8(5), 389.394. doi: http:// doi.org/10.1186/cc2955

Cardenas, A. (2006). Sistematización metodología PUI. Medellín: Alcaldía de Medellín. Recuperado de http://aprendeenlinea.udea.edu.co/lms/moodle/ file.php/76/PUINOR_Sistematizacion_metodologia_Noviembre-2006. pdf dato 
Departamento Administrativo de Planeación Municipal - Unión Temporal Plan de desarrollo Comuna 13. (2009). Plan de desarrollo local comuna 13, San Javier. Medellín.

Dovey, K., \& King, R. (2012). Informal Urbanism and the Taste for Slums. Tourism Geographies, 14, 275-293.

Dürr, E., \& Jaffe, R. (2012). Theorizing Slum Tourism: Performing, Negotiating and Transforming Inequality. European Review of Latin American and Caribbean Studies, 113-123.

Frenzel, F., \& Koenz, K. (2012). Slum Tourism : developments in a young field of interdisciplinary tourism research. Tourism Geographie, 195-212.

Giraldo, F., García, J., Ferrari, C., \& Bateman, A. (2009). Urbanización para el desarrollo humano. Politicas para un mundo de ciudades. Bogotá: UN-Habitat.

Guevara, T. (2015). Abordajes teóricos sobre las transformaciones sociales, económicas y territoriales en las ciudades latinoamericanas contemporáneas. EURE - Revista Latinoamericana de Estudios Urbanos Regionales, 5-24.

López Zapata, L., Sepulveda, W., \& Gómez Gómez, J. (2015). El rol del turismo en los planes de ordenamiento territorial de Medellín. Annais Brasileiros de estudos turísticos, 26-34.

Migración Colombia - Calculos OEE - Mincit. (2016). Estadísticas Nacionales - Flujo de Turistas - Turismo Receptor. Recuperado de http://www.citur.gov.co/ estadisticas/df_viajeros_ciudad_destino/num_viajeros $/ 2$ ? $t=1$

Montoya, R. N. (2014). Urbanismo social en Medellín: una aproximación a partir de la utilización estratégica de los derechos. Estudios Políticos, 205-222. Recuperado de http://aprendeenlinea.udea.edu. co/revistas/index.php/estudiospoliticos/article/view/20203/20779197 Nogué i Font, J. (1989). Paisaje y turismo. Revista estudios turísticos (103), 35-46.

Nogué i Font, J. (1992). Turismo, percepción del paisaje y planificación del territorio. Revista de estudios turísticos (115), 45-54.

Quinchía, S. (2013). Discurso y producción de ciudad:un acercamiento al modelo de urbanismo social en Medellín, Colombia. Cuadernos de vivienda y urbanismo, 122-139.

Rios-Milagres, V., Barbosa E., \& Souza, L. (2012). Observando la comunidad local y su involucramiento con el turismo: un abordaje perceptivo sobre el paisaje del distrito Taquarucu, Palmas-TO, Brasil. Estudios y Perspectivas en Turismo, 21(6), 1609-1629.

Subsecretaría de transporte y tránsito, Subsecretaría ténica - Municipio de Medellín. (2008). Estudio de la oferta de transporte público colectivo en el parque Arvi corregimiento de Santa Elena. Medellín.

Urry, J. (2004). La mirada del turista. Lima: Universidad San Martín de Porres. Vargas, L. (1994). Sobre el concepto de percepción. Alteridades, 4(8), 47-53. 
